\title{
Distribution of marketing research material to universities: The case of Archive of
}

\section{Market and Social Research (AMSR)}

$$
\text { By }
$$

Dr Nektarios Tzempelikos, Principal Lecturer in Marketing, School of Management, Faculty of Business and Law, Anglia Ruskin University, SCI 708, East Road, Cambridge, CB1 1PT, UK

Direct line: +44 (0)8451962664 email: nektarios.tzempelikos@anglia.ac.uk

Dr Kaouther Kooli, Principal Lecturer in Marketing, The Business School, Bournemouth University, Executive Business Centre-EB401, 89 Holdenhurst Road, Bournemouth, BH8 8EB

Direct line +44 (0)1202968709 email: kkooli@bournemouth.ac.uk

Professor Merlin Stone, Visiting Professor, St Mary's University Twickenham and Portsmouth University

School of Business, Law and Society, St Mary's University, Waldegrave Road, Twickenham, London, TW1 4SX

Direct line 02082404062 email merlin.stone@ stmarys.ac.uk

Dr Eleni Aravopoulou, Senior Lecturer in Business Management,

School of Business, Law and Society, St Mary's University, Waldegrave Road, Twickenham, London, TW1 4SX

email: eleni.aravopoulou@ stmarys.ac.uk

Robin Birn, Senior Lecturer in Marketing

School of Business, Law and Society, St Mary's University, Waldegrave Road, Twickenham, London, TW1 4SX email: robin.birn@stmarys.ac.uk

Emmanuel Kosack, Associate Lecturer in Business Management School of Business, Law and Society, St Mary's University, Waldegrave Road, Twickenham, London, TW1 4SX

email: emmanuel.kosack@stmarys.ac.uk 


\title{
Distribution of marketing research material to universities: The case of the Archive of Market and Social Research (AMSR)
}

\begin{abstract}
Purpose - the aim of this study is to understand how content relating to marketing and market research is distributed to and within universities. The focus of the study includes the behaviour of all those in this market for information, namely suppliers (whether content generators, aggregators, packagers or distributors of content) of marketing research, university staff, and students.

Design/methodology/approach - The case study method was implemented to collect data. The case study focuses on UK Higher Education. Specifically, the authors use the case study of the newly developed Archive of Market and Social Research (AMSR) to explore how content relating to marketing and market research is distributed to and within universities. The research involved personal interviews with 15 librarian senior managers selected from 14 universities.
\end{abstract}

Findings - The interviews with librarians provided insight about how AMSR could be distributed to university libraries and how it could be accessed. The findings highlight the role of university academics in specifying the content of marketing and market research. They focus on 'real world' management problems to deliver research with impact and relevant teaching. Therefore, they need company and industry information and are more likely to use current sources.

Research implications - The study maps the process of acquisition of marketing and market research content by universities and identifies the different roles involved in this process. The study is in line with the emerging literature that focuses on the role of education in explaining the relevance gap in marketing research. The study contrasts between the situation in the university market and industrial buying, and adds to our understanding of the complexities associated with the distribution of the marketing research material. The result is expected to be a much sharper focus for the marketing of the archive material, leading to greater use of recent high-quality market research by marketing educators, and changes to marketing and market research syllabuses. 
Practical implications - The study provides insight about how suppliers (whether content generators, aggregators, packagers or distributors of content) of market and marketing research should market to universities and ensure the use of their information resources by students and teachers and how they should. The findings of the study contribute to understanding customer needs and shaping a new service product proposition. In addition, the study provides insight into how university students and staff access and should access commercial research on marketing from the market research industry (in particular from the Archive of Market and Social Research) and use it in their learning, so that their knowledge will be more up to date and their employability will be increased.

Originality/value - The paper adds several insights to the issue of distribution of marketing research material to universities. The paper relates to the marketing of information resources to universities, specifically to the work of the Archive of Market and Social Research, in marketing their information assets to universities, and more specifically the relationship between the "push" of suppliers, libraries, journal and textbook suppliers and information aggregators (such as EBSCO and JISC) and the pull coming from academic researchers and lecturers, who might use this information in their teaching and research. The present study can be seen as a classic case study of understanding of buyer behaviour, but in a modern world of information platforms, aggregation and the digital economy.

Keywords: marketing research, marketing education, information technology, managerial relevance, universities, library, archive, purchasing.

\section{Introduction}

Recent years have seen a widespread debate about the relevance of academic research to business practice in marketing. Although the research conducted in the marketing field is often of high quality and magnitude, it mostly does not reach managers. Scholars have long noted the role of education in explaining the academic/practitioner gap (e.g. Baker and Holt 2004; Lee and Greenley 2010; Danneels and Lilien 1998). A key message of these studies is that there is a relevance gap in education, in that academic knowledge is detached from the realities of the business world. Interest in 
this topic in the academic community is strong and growing and signals the need to explore whether marketing educators have failed to deliver the theory and frameworks that could solve real-world problems and how business school education could address this relevance gap, especially in light of the educational potential of the internet and digital technologies.

Several researchers have examined the 'gap' between the current marketing curriculum and its response to digital disruption (Brennan 2004, O’Brien 2016, Langan, Cowley, and Nguyen 2019). Huggins (2019) perceives there to be a huge gap between the skills academia is providing to their students and the skills needed to be proficient in our current digital marketplace, citing a Glassdoor (2018) blogpost entitled, "15 More Companies That No Longer Require a Degree - Apply Now." Notable companies on that list include Google, Apple, IBM, and the Bank of America, all with jobs in the area of marketing communications or in customer/user experience. The post argues that this situation leads universities two options; either hire part-time professors that work in the digital arena or provide more theory-laden classes with minimal practical skill-building opportunities, widening the gap between marketing practice, research and education. It can also be argued that there has been an evolution in the market research context: technology is changing, and what needs to be researched is also changing, so academics have a greater need to be up to date. This involves rethinking the content of marketing research and education in order to be in line with the need of employers. A key role in all this is played by suppliers of marketing research (Stern and Tseng 2002). To date, the main focus of the work (Yi 2018; Gupta and Savard 2011) has been on the attitudes, perceptions and behaviour of university librarians responsible for management collections, in relation to the acquisition of content, how it is made available, how its usage is monitored and how decisions are made about the deletion of content.

The aim of this study is to understand how content relating to marketing and market research is distributed to and within universities. The focus of the study includes the behaviour or all those in this market for information, namely suppliers (whether content generators, aggregators, packagers or distributors of content) of marketing research, university staff, and students. 
The article relates to the marketing of information resources to universities, specifically to the work of the market research industry body, the Archive of Market and Social Research (AMSR, hereafter), in marketing their information assets to universities, and more specifically the relationship between the "push" of suppliers, libraries, journal and textbook suppliers and information aggregators (such as EBSCO and JISC) and the "pull" coming from academic researchers and lecturers, who might use this information in their teaching and research. The newly developed AMSR (www.amsr.org.uk) aims to liberate the rich data and commentary generated since the 1950 s by the market and social research industry in the UK, making it available to support social and commercial progress, which includes making it available to universities to enhance the research and learning in business and social science disciplines.

The present article can be seen as a classic case study of understanding of buyer behaviour in business-to-business context, but in a modern world of information platforms, aggregation and the digital economy. The article is positioned in the broader area of marketing research in business-tobusiness markets, focusing on the context of education. The literatures covered in the article include marketing of information and information technology, library marketing, purchasing, distribution, key account management, skills, and issues relating to ensuring relevance and up-datedness.

Having outlined the background and the purpose of the study, we next discuss marketing education and the need for accurate marketing research as well as the key characteristics of distribution of marketing research. Then we present the method and the findings of the study and conclude with a discussion of the findings, the limitations of the study, and suggestions for future research.

\section{Marketing education and the need for accurate Marketing research}

\subsection{Market changes - the current state of academic journals}

Perhaps the most notable points about this market (material related to market and marketing research) relate to its size and growth (Johnson, Watkinson, and Mabe 2018). There are about 10,000 journal publishers, with over 33,000 scholarly peer reviewed English language journals. Over 3 
million articles are published a year. The number of articles published and the number of journals are both growing at about $3 \%$ or more a year. China (19\%) is now producing more papers a year than the US (18\%), while India (5\%) is rapidly rising, having overtaken Germany, Japan and the UK, each on 4\%. The main journal publishers in the West, Elsevier, Springer Nature, Taylor \& Francis, and Wiley, make group (so-called "big deal") contracts with universities for access to their journals (Morais, Stoy, and Borrell-Damian 2019). The costs of these contracts is rising steadily, so government research organisations are insisting that scholarly research is published in open access repositories in universities, in an attempt to weaken the bargaining power of the major journal companies (Science Europe, 2018). However, the underlying rise in the number of university students at all levels, supported by the requirements by employers of all kinds for more graduates (and in some cases doctorates) is sustaining this demand. The demand for relevance is also stimulating the demand for and the supply of applied research, as students working on projects need access to a mix of material, some of it theoretical, some of it empirical.

Journal publishers perform a range of valuable functions, which have been enumerated in many publications and blogs, such as that of Anderson (2018). They include the soliciting, assessing, aggregating and integration of content, as well as its production, distribution, marketing and hosting. Authoring and review management are very labour-intensive, but increasingly automated. Workflow analytics have become very important for checking the performance of journals and authors. These are just a few of the tasks, many of which AMSR would have to do if it decided to go it alone! One point of particular relevance to AMSR is the rise in the sales of individual articles from journals and individual chapters from books, although sales of whole journal subscriptions still dominate (Johnson, Watkinson, and Mabe 2018).

Data on the number of reputable management journals seems to be harder to find, but the Scimago (2019) ranking gives nearly 178 marketing journals (although many of these are not pure marketing). The globalisation of enterprise and the rise of the digital economy have posed particular challenges to academic communities, encouraging them to update their research and make it more 
relevant internationally but, according to McDonald (2003, 2009), Hughes et al. (2018), Stone (2013) and others, this has not led to the production of research that is more relevant to industry needs.

\subsection{Relevance gap in marketing education}

The issue of a "relevance gap" in marketing research has usually been raised in the form of the "rigour vs. relevance" debate. Although research conducted in marketing is often of high quality, it fails to reach managers to any great extent (Jaworski 2011; Lilien 2011; Reibstein et al. 2009). The research done by marketing academics is typically not read and appreciated by practitioners, regardless of how relevant to practice this research is.

This divergence between academic practice, whether in teaching or research, and industry practice, occurs in marketing education too, as noted by Nunan and Di Domenico (2019) and Nunan (2016, 2017). Nunan's work identifies the threat to market research of digital marketing and new types of customer data, in many cases collected directly from customers or supplied by intermediary data providers, replacing wholly or partly traditional fieldwork-based data collection on which market research curricula are focused. This threat started with the rise of customer relationship management as a concept and the implementation of many database systems which allowed the collection and storage of large amounts of customer data. The rise of this approach was documented by Stone et al. (2019). In the above-cited works, Nunan identified many actions through which those teaching marketing research can make their work more consistent with industry practice, such as: 1. Moving market research teaching from data collection to analysis, insight, communication and application, especially identification \& synthesis of data, 2. Focusing more on communication and story-telling, from identification of stakeholders to exploring different forms of communication, 3. Integrating their teaching with other marketing disciplines, 4. Modernising their curriculum to include defining consumer/customer insight and exploring its application, 5. Moving from demographics, usage and attitudes to interpretation of social media, and 6. Giving more coverage to ethical issues, e.g. trust, privacy, data theft \& fraud. 
Of special relevance to the AMSR is Nunan's recommendation concerning building a database of UK marketing academics for an awareness campaign. This recommendation should be extended to other academic areas e.g. those who might be interested in social and health research. This could be done by classic database techniques or by building a user group on LinkedIn.

On a broader level, literature has identified many reasons for marketing education not being sufficiently close to practice. One possible reason for the divergence of academic market research practice from business needs is documented by Sheoran at al. (2018). They identify (but do not criticise) the focus on techniques which are academically attractive but of limited value in business e.g. game theory, structural equation modelling. Your authors suggest that behind this lies a more important reason, hinted at in the works by Nunan cited above, that academic researchers are divorced from commercial practice (if they were ever connected with it), and tend to use techniques which suit their own research objectives, which are generally (as identified in McDonald 2003, 2009; Hughes et al. 2018; Stone 2013) to achieve publication in a well-ranked academic journal by doing in-depth research into a tightly defined but rather static sample of customers. Structural equation modelling has become very popular, for example, but its application is in most cases aimed at defining the characteristics of a complete sample (including which factors determine the dependent variable directly and which intermediate the effects of other variables), rather than identifying different segments within the sample, as would be normal commercial practice.

From a rather different perspective, Gummesson (in Lee \& Greenley, 2010) points out that education has been built upon a deductive approach that aims to explain reality through preconceived theory and does not allow practical experiences to inform education (an inductive approach). As a result, education tends to be dominated by 'textbook knowledge', much of which is out-dated. Most recent textbooks report findings from the 1990s or 2000s and tend to address business phenomena with a delay. However, reality runs faster than textbooks. It is important therefore for academia to better understand what types of information practitioners perceive to be useful (Hutt and Speh 2007; Ottesen and Grønhaug 2004). 
Literature has identified ways of moving towards making marketing research more relevant to practice. Reibstein et al. (2009), in their seminar study, concluded that the prevailing paradigm of empirical studies in marketing is data-driven. That means that we begin with a data set, we analyse the data, and only then do we ask where it might be applied. The resulting conclusions may be of some relevance to the academic, but it is doubtful whether they offer useful and applied guidance to practitioners (Reibstein et al. 2009). Brennan, Tzempelikos and Wilson (2014) argue that a better approach is to have a managerial problem (or problems) as a starting point and, based on this problem, to design the methodology of a study. The result would be applied research that addresses managerial issues even if no advanced methodologies or new theories are proposed. Marketing research should shift from problem-finding to problem-solving (Hughes et al. 2012).

Furthermore, Joseph-Richard and Jessop (2018) recommend that academics to go beyond limited functional conceptions of research-informed teaching (RIT), embracing the idea that knowledge is provisional and commitment to lifelong exploration and impactful learning are developed in students. Along these lines, Cordingley (2008) proposes that transformation of knowledge from research into classroom practice involves a mix of complex processes, some of which need specialist mediation and dedicated resource, and that reflecting on knowledge transformation as Continuing Professional Development (CPD) and learning helps to elucidate some of the steps along the way.

\subsection{Grey literature}

One recent trend in management literature has been the strengthening of what academics disparaging call "grey" literature (Adams, Smart, and Huff 2017), publications outside traditional academic peer-reviewed papers, a category into which most AMSR literature falls. This covers a range of different outputs, such as academic articles and discussion papers which were not or have not yet been published or were rejected, articles in non-academic media, bibliographies, book chapters, company reports, conference abstracts, data sets, dissertations, theses and other student research reports, emails, personal correspondence, wiki articles, blogs, newsletters and other less formal communications among others categories. 
Incorporating grey literature - the diverse and heterogeneous body of material available outside, and not subject to, traditional academic peer-review processes - can make a variety of positive contributions to subsequent inquiry and practice. Several scholars have used grey literature to extend the scope of findings in their studies by incorporating relevant contemporary material in dynamic and applied topic areas where scholarship lags; they have explored novel fields of enquiry, and have validated or corroborated findings from the academic literature (c.f. Adams, Smart, and Huff 2017). In addition, many scholars use grey literature to make their work more impactful and bridge the research-practice gap (Deadrick and Gibson 2007; Huff 2000). Grey literature has been described as a means of gathering and analysing evidence that can answer practice-relevant research questions (Tranfield, Denyer, and Smart 2003). Although high-quality, peer-reviewed articles should be the a source of information for both researchers and students, we believe that the variety and relevance of academic inquiry can be increased by considering the diverse wisdom gained from grey literature.

\subsection{Thought leadership and role of the internet}

In line with the above discussion, an emerging literature category worthy of intention is socalled "thought-leadership" literature, produced by consultancy, research, analyst and many other types of organization, to influence - directly or indirectly - their target markets (Ernst, Cooperstein, and Dernoga 2011). Much of this research is very practical, focusing on current issues faced by management and recommendations as to how to deal with them.

An example of this can be seen in the rise of think tanks, such as the McKinsey Global Institute (MGI), established in 1990, with the specific objective of providing research to inform business leaders. Such think tanks have become so common that they are now analysed and indexed (McGann, 2019), with MGI rated as the leader. McGann identifies over 2000 think tanks in North America and a slightly larger number in Europe, with the number in Asia slightly smaller but growing rapidly, and a slightly smaller number again in the rest of the world. They not all business-focused, with some focused on public policy issues. These think tanks may issue anything from a few to hundreds of reports a year. 
The rise of think tanks is important for that part of the AMSR content that might support social and economic research, for that is the focus of many of the think tanks and their publications, for example, interpreting the past as a stronger basis for forecasting the future. Given the importance of the archive to this kind of research, it might make sense for the AMSR to consider partnership with a think tank or a consultancy which provides large amounts of thought leadership.

\section{Distribution of marketing research}

A thorough understanding of how effective distribution of marketing research can be achieved requires an assessment of how faculty staff and students search, find, and use of the research information. In the following paragraphs we go through each of the key elements of the mechanism of distribution of marketing research, drawing on the case of AMSR.

\subsection{How university staff find and use research information and incorporate it into teaching}

University lecturers, researchers and students use academic journals and grey literature for various purposes. For students, "relevance" may be a more important issue than for staff, as the employability (or lack of it) of students is seen to be partly related to how far they have engaged with industry, the data arising from it and the concepts that they use in practice, before they leave university. In practice, undergraduate students mainly use literature for assignments. The depth of use varies dramatically, according to the level the student is studying at and their intellectual ability. The sources most commonly used at lower levels are those recommended by tutors, but once a student starts to research topics in depth rather than to answer standard essay questions, particularly if the focus is on particular industries or companies, the depth of search changes rapidly, towards the deep research carried out by masters and - in even greater depth - by doctoral students.

The literature students seek to support their assignments is partly determined by reading lists issued by lecturers, and partly by the guidance they receive from lecturers concerning the literature they need to use for their specific assessment projects and dissertations. Lecturers are asked by libraries to confirm the books and journals they require for their modules, and these are included in the module guides used by students but also by library staff for identifying requirements. In most 
universities, library staff maintain literature requirements on systems which are integrated to various extents with the learning management systems used by lecturers to post content and management assessments. Creating awareness among lecturers of which journals and sources are available is an important part of publishers' marketing. For this reason, AMSR needs to consider in what form they make material available and how they guide users on how to use the sources. AMSR should consider producing guides to its content and even books or journal articles analysing the content.

The content required to be used is determined by the course syllabi, which in the UK are all included in the validation process for degrees. Although the detailed listing of material to be used may be changed, the course content forms part of the validation process, and in some cases, this involves professional accreditation, which may require the use of certain sources (e.g. Market Research Society, Chartered Institute of Management, Chartered Institute of Marketing). In any case, the AMSR must consider the validation and revalidation cycle that universities are required to go through if the archive is to become established as a central source of information. Each degree programme has its own regular validation and revalidation cycle, as part of universities' quality processes, so in marketing any particular source, it is important to understand which modules would benefit from use of AMSR. This is probably best done through discussions with the members of staff responsible for the relevant modules. In each university, if its teaching covers all the areas where the AMSR has material, there might be several staff in management, social sciences, health and other areas who should be made aware of the existence of the AMSR, so that they can factors its content into their teaching and module planning.

\subsection{Search behaviour of students}

The above relates to "pushing" AMSR information to potential users. But "pull" of users searching for information is equally important. Achieving success here requires understanding users' search behaviour. For deeper searches, students generally use Google and Google Scholar, and their university's own library search engine (which indexes not only the titles and summaries but the full content of articles). A common practice among students is to carry out searches using Google and Google Scholar, and where these searches yield results which are not publicly available (e.g. via 
Research Gate or Academia.eu or other posting sites, through university open access archives), to search their own library to see if the library's subscription includes the required article. Given the increasing drive towards open access, we expect open browsing to be used with increasing frequency.

This heightens the importance of grey literature, which is more likely to be found via a Google search than by searching more academically focused indices e.g. Web of Science, Scopus, particularly since the suppliers of many types of grey literature are keen to have it accessed free, and so focus strongly on making their content likely to be listed in the first or early pages of any search. Some researchers are wise to this, and may first use Google Scholar to identify "respectable" research, and then move to Google with more specific search terms to find other works published by the same researcher or supplier, or a public version of an article (e.g. an earlier draft) that is not available publicly in its final form. Google Scholar will also give an indication of the usefulness and aacademic respectability of the work, through its citation analysis.

\subsection{Characteristics of the distribution model}

The market in which AMSR plays can be portrayed as a classic push-pull business to business market, with lots of content being pushed at customers (students, academics, companies, public sector agencies, charities etc.) and the latter deciding how and when to use it, However, as with many other markets, intermediaries have evolved, and their work has been made much easier by the use of digital approaches. This can be seen when a new concept begins to emerge. It is now easy for content providers to track emergence and then identify the need for more content of a particular topic. An example of this is the idea of the "business model", the emergence and use of which has been tracked by many authors in terms of the number of academic articles featuring it (Stott, Stone, and Fae 2016; Zott, Amit, and Massa 2010) and their growth.

Where content pricing strategy is concerned, Johnson, Watkinson, and Mabe (2018) identified several approaches and trends in the pricing of academic content. Individual journal subscriptions have fallen in favour of "bundles" or electronic content, covering several journals. Nearly all journal publishers offer bundles, and larger journal firms have been acquiring smaller publishers in an attempt 
to strengthen their bundles, while smaller publishers sometimes join with other publishers to offer bundles. Bundles now offer non-journal content, such as datasets, reference works and e-books.

Most libraries buy in bundles, as this simplifies the buying decision. University libraries are often in buying consortia, increasing their bargaining power. Prices charged may reflect previous print pricing plus a top-up to allow electronic access. A deal in which all a publisher's or publishing consortium's output is offered to a consortium is known as the "Big Deal". Other pricing models which existed or have existed include pricing by usage (where databases may be limited to a maximum number of simultaneous users), by tiers according to institution size, by customer type (e.g. university, hospital) and flat rate pricing for everything in the bundle.

\section{Methodology}

The case study method was implemented to collect data between November 2018 and October 2019 (Table 1). The case study focuses on the UK Higher Education. A protocol was designed according to Yin's (2013) guidance. In-depth interviews were conducted to find how content relating to marketing and market research is distributed to and within universities and to discover patterns in research-based resources acquisition and decision making, their use in teaching and in student projects in marketing departments as well as patterns in the use of the concepts and knowledge in marketing after university, and how publishers and distributers of content see the evolution of the market (Pera, Occhiocupo and Clarke 2016; Bryman and Bell 2015). Table 1 below provides details about the interviewees. Empirical saturation criteria were used (Tracy 2010).

Fifteen Librarian Senior Managers (two interviews were carried out in one university) selected from fourteen universities that participated to this study. Libraries play a key role in supplying marketing academics and students with research-based resources. This study emphasises their role as suppliers of research-based information. Triangulation is ensured via secondary sources e.g. reports, reviews, web links or other documented sources of information in the public domain (Eisenhardt, 1989; Yin, 2013). 


\subsection{Data analysis}

Some interviews were tape-recorded and transcribed, while others took place via e-mail. The responses were coded and categorised to generate themes (Miles and Huberman 1994). To ensure external and internal validity and internal reliability, data were coded by different investigators including one that is external to the study (Pera, Occhiocupo and Clarke 2016) and from different stakeholders i.e. the fourteen universities selected for the study.

Table 1: Interviewees Information

\begin{tabular}{|c|c|c|c|}
\hline \multirow[b]{2}{*}{ University } & \multicolumn{3}{|c|}{ Method } \\
\hline & Email questionnaire & $\begin{array}{c}\text { Phone or face to face in- } \\
\text { terview }\end{array}$ & $\begin{array}{c}\text { Number of interviewees } \\
\text { per University }\end{array}$ \\
\hline 1 & $\mathrm{x}$ & & 1 \\
\hline 2 & $\mathrm{x}$ & & 1 \\
\hline 3 & $\mathrm{x}$ & & 1 \\
\hline 4 & & $\mathrm{x}$ & 2 \\
\hline 5 & & $\mathrm{x}$ & 1 \\
\hline 6 & $\mathrm{x}$ & & 1 \\
\hline 7 & $\mathrm{x}$ & & 1 \\
\hline 8 & $\mathrm{x}$ & & 1 \\
\hline 9 & $\mathrm{x}$ & & 1 \\
\hline 10 & & $\mathrm{x}$ & 1 \\
\hline 11 & $\mathrm{x}$ & & 1 \\
\hline 12 & & $\mathrm{x}$ & 1 \\
\hline 13 & & $\mathrm{x}$ & 1 \\
\hline 14 & $\mathrm{x}$ & & 1 \\
\hline
\end{tabular}

\section{Findings}

The data emphasizes the role of university academics in specifying the content of the marketing and market research. Users of research-based information include academics as researchers and teachers, students and other staff but also, where they are allowed access, alumni and partners i.e. university partners elsewhere in the UK or abroad. Students use this information mainly to develop 
their projects, assignments and dissertations (they may be required to access specific papers for individual assignments) and to prepare for future jobs and for career development.

Table 2 highlights the main sources of marketing and market research used. The required mix and depth of materials depends on the courses offered and the size of undergraduate and postgraduate populations in each of the 14 universities. The librarians are prompted by (1) academics e.g. through expressing their needs and alerting librarians to new sources, and, (2) content providers that constitute a source of information on new content, and their communications are treated seriously.

Table 2: Sources of marketing and market research and available content

\begin{tabular}{|c|c|c|}
\hline Sources & Content & Discipline \\
\hline Business Source Complete & $\begin{array}{l}\text { Premium full-text content and } \\
\text { peer-reviewed business jour- } \\
\text { nals }\end{array}$ & $\begin{array}{l}\text { Business, e.g. marketing, management, ac- } \\
\text { counting, banking, finance and more. }\end{array}$ \\
\hline ABI/INFORM & $\begin{array}{l}\text { Business database containing } \\
\text { thousands of journals. }\end{array}$ & $\begin{array}{l}\text { Business and economic conditions, corporate } \\
\text { strategies, management techniques, as well } \\
\text { as competitive and product information }\end{array}$ \\
\hline Emerald Insight & $\begin{array}{l}\text { A portfolio of over } 300 \text { jour- } \\
\text { nals, more than } 2,500 \text { books } \\
\text { and over } 1,500 \text { teaching cases. }\end{array}$ & $\begin{array}{l}\text { Accounting and finance, management, mar- } \\
\text { keting, education, information studies and } \\
\text { engineering. }\end{array}$ \\
\hline Elsevier/ScienceDirect & $\begin{array}{l}\text { Platform of peer-reviewed } \\
\text { scholarly literature. It includes } \\
\text { thousands of books, journal ar- } \\
\text { ticles, and other reference ma- } \\
\text { terials. }\end{array}$ & $\begin{array}{l}\text { Accounting and finance, management, mar- } \\
\text { keting, education, information studies and } \\
\text { engineering. }\end{array}$ \\
\hline Sage & $\begin{array}{l}\text { Platform of peer-reviewed } \\
\text { scholarly literature. It includes } \\
\text { thousands of books, journal ar- } \\
\text { ticles, and other reference ma- } \\
\text { terials. }\end{array}$ & $\begin{array}{l}\text { Accounting and finance, management, mar- } \\
\text { keting, education, information studies and } \\
\text { engineering. }\end{array}$ \\
\hline The MarketLine database & $\begin{array}{l}\text { MarketLine supplies the in- } \\
\text { formation which is accessible } \\
\text { via the Company Profiles link. }\end{array}$ & $\begin{array}{l}\text { Business information covering the automo- } \\
\text { tive, consumer, energy, financial services, } \\
\text { healthcare and technology sector. }\end{array}$ \\
\hline LibGuide & $\begin{array}{l}\text { Library Subject Guide - direc- } \\
\text { tory of specialist resources. }\end{array}$ & $\begin{array}{l}\text { Various subjects, general library services, or } \\
\text { even individual courses or assignments. } \\
\text { They often feature databases/resources that } \\
\text { are most often used for a subject and re- } \\
\text { search tips specific to a given field. }\end{array}$ \\
\hline $\begin{array}{l}\text { Freely available statistics } \\
\text { from government (e.g. Office } \\
\text { of National Statistics) and } \\
\text { other public organizations }\end{array}$ & Large scale surveys. & Diverse fields. \\
\hline Case Study Clearing House & Cases studies. & Business \\
\hline
\end{tabular}




\section{Emerging themes}

In line with the research aim, which is to understand how content relating to marketing and market research is distributed to and within universities, the following themes were identified:

\subsection{Marketing and market research content access and use}

Librarians authorise access to this content via universities library interface sites (1) off campus via IP recognition and Shibboleth - a "federated" Identity Management system i.e. the UK Access Management Federation, for authentication and authorization to members of a common "federation and, (2) on campus, via the university's VPN network. Most access to this content is electronic, particularly for journals which can be accessed both directly from publisher sites and through aggregators. Books, particularly textbooks are often accessed physically. However, publishers increasingly provide multiple license e-copies, making books more accessible online. Universities also have to comply with the Equality Act 2010 and make resources accessible for disabled students and academics e.g. blind and partially sighted.

Interviewee 10 stated "We are now under some new legislations. We are obliged to provide resources to people who are partially sighted or have other disability issues. For example, they might need a different format of books, they might need different types of an e-book or material scanned in a different way. The database providers, however, are usually aware of these accessibility issues and disability compliance. Different students for example, have different accessibility needs, so we look at those on a case by case basis".

Students use different software such as library search engines to access and manage resources and access reading lists for modules e.g. Summon, and to manage these resources e.g. Talis Aspire, Primo online catalogue. They particularly like to be able to retrieve previous search results. Also, according to the interviewed librarians, a good visual interface is important for encouraging students to browse and for demonstrating the resource to them.

Interviewee 6 stated "The majority of our users use a hybrid of physical materials and electronic resources. For physical resources it is based on books with a very small usage of journals. 
For electronic resources they utilise databases, journals, and eBooks. The databases include market research, financial databases, real estate portals, and economic portals".

Interviewee 2 stated "Information literacy is the decision-making process, knowing what you need, where to find it and adding value by repurposing the material".

Interviewee 7 stated that "Users like to use a search bar to retrieve results. A good visual interface is also important though, for encouraging them to browse and in demonstrating the resource to them".

\subsection{Marketing and market research content purchasing process}

The purchasing process of buying marketing and market research content has been identified based on the data analysis. The purchasing process can vary from one university to another, but there are some common key elements.

\subsubsection{Need recognition}

The process usually starts with a need for marketing and market research content expressed by academics and students. For example, a new course will require the acquisition of new resources. This need to purchase the content can also be triggered by organisations i.e. suppliers of content or aggregators that suggest new contents to university librarians.

Interviewee 4 stated "...if for instance, a new unit was created, then we would work with those lecturers and work on that. if there was a review of a programme, for instance the postgraduate courses, the accounting and finance, and business postgraduate courses are up for review next academic year, then part of the process is talking to whoever is going to be teaching on that to make sure that the resources that we have got are appropriate and if they feel that we need a new resource then we would have to put together a business case to get extra funding for that".

Interviewee 5 stated “...if new courses needs resources to acquire books or subscriptions, we check funding is high enough and if that changes we will discuss with senior member and eventually with line managers to see if they are willing to purchase a new archive". 
Interviewee 6 added “...New resources are usually identified by individual departments/staff members as being of use to their students. These will then be investigated to look at costs and whether we have alternative sources which may offer similar data. Others are based on being contacted by providers with product offers, which we will investigate in a similar manner".

AMSR could be interesting for postgraduate students but presents less interest for UG students, unless the students have a specific assignment in areas where AMSR has deep records e.g. studies of consumption habits. Undergraduate students are looking for very current information which makes the AMSR less appealing for them.

\subsubsection{Selection of the marketing and market research content}

When considering the different options, university librarians use various criteria including: the possibility of using the SCONUL inter-library process, the price of the content, the quality and reliability of the offering, including deals (e.g. JISC deals and publisher deals) and their liaison with supplier and what they offer to the university. In addition, they consider practical selection criteria e.g. ease of set-up for librarians and ease of use for students, preferring options where they do not have to register users.

Interviewee 1 stated that "We consider appropriate JISC deals available to us for the resources we are looking at purchasing or renewing”.

Any new source provider needs to approach both the librarians and academics. If the source is free, it needs to provide information on what they can offer to the university e.g. videos, tutorials, other resources, they can send to students and academics. New sources are sometimes trialled to see if users access them.

Interviewee 10 stated "identification and acquisition of resources are dependent upon, cost, use and how accessible it is ... Ease of use for students, How easy is it to set up, Price, Quality of the offering, Reliability, Deals - JISC deals and publisher deals, How we can liaise with the supplier, what they offer us". 


\subsubsection{Acquisition of marketing and market research content}

The decision to purchase the marketing and market research content are made at different levels within the universities e.g. the university librarians and the Head of Department or the Dean in some other cases, provide the final sign-off of for the purchase to be done;

Interviewee 14 stated "Lecturer requests a new subscription - subject librarian investigates costs - cost and rationale passed to Librarian - if approved, passed to Dean of relevant Faculty for final approval. No difference between disciplines or levels of academic seniority."

Universities libraries acquire marketing and market research content either directly from the publishers or from some aggregators e.g. Mergent includes the Investext database.

During both the selection and buying process, university librarians are supported by organisations e.g. SCONUL, inter-library bodies, professional associations (e.g. Chartered Institute of Librarians and Information Professionals), discipline-focused library associations, groupings of academics, professional societies and individuals e.g. leading researchers/authorities. This varies by university, course and type of material.

Interviewee 10 reinforced that "JISC is useful because they negotiate deals and they got agreements and sometimes they are very straight forward they go and talk to the providers. They look for academic deals that all universities can go for, they are however, tiered-based on how many students you have. And it is standardized. S,o it makes it a lot easier for university procumbent team and its much more straightforward. However, sometimes you can get a cheaper deal if you go directly to the supplier rather than through JISC. Nevertheless, you may not get some of the standardized stuff that JISC provides. Generally, JISC negotiated deals are preferred even the price is slightly higher as they come with certain guarantees and quality".

\subsubsection{Feedback on and tracking the use of the content}

To monitor user satisfaction, university librarians collect feedback and track the use of the acquired marketing and market research content. Some of the interviewed universities librarians had carried out research into their users' experience, while others analyse access statistics to find out information 
such as which courses students who use the material are on and which staff are big users. Tracking is easier when the content is a journal, because journals have extensively developed tracking of articles accessed by users, partly for citations tracking purposes.

Whatever the size of subscription, in the current tight budgetary situation, all subscriptions are evaluated for frequency of use, and poorly used subscriptions are not renewed. Academics' approval is sought before cancelling any subscription.

Interviewee 4 stated "...we are constantly reviewing our resources. The problem with the resources is they are extremely expensive, so, we are talking tens of thousands of pounds to subscribe to these resources, so it is something if we take on a new resource, then we have to get more funding. So, we are constantly getting, seeking feedback from academics, particularly about whether we think, they think what we are subscribing to is appropriate or not. So that is part of the faculty teams' job, is to work with the academics and talk to them about whether the resources that we subscribe to are appropriate for the courses".

Interviewee 5 stated "As professionals we look around annually for annual subscription that is no longer required"

\subsection{Marketing and market research content buying roles}

Different roles in marketing and market research content acquisition could be identified based the data analysis. These are:

\subsubsection{Identification of content}

Academics suggest marketing and market research content to librarians, based on their needs for teaching and research. However, academic departments sometimes buy databases for their researchers directly from the source, without involving libraries in their selection or payment.

Interviewee 9 stated "Librarians decide on what material to purchase, we may be alerted to data/archives by academics but the decision to purchase is up to us if it comes out of the Library budget." 


\subsubsection{Acquisition and negotiation of content}

University librarians play different roles in the acquisition and promotion of marketing and market research content. There are specific individuals in the university organisation that are responsible for particular schools/departments. The breadth of their responsibility varies by size and specialization of university. For example, in some very large universities there may be more than one member of staff responsible for a given department. Their roles and responsibilities range from providing academic staff with the needed content, liaising with content providers and aggregators to educating students in how to use research resources and helping individual students find material they need. Key to their role is their responsiveness to requests for information, updating of reading lists and unit handbooks. Hence, they have to build sound collaborative relationships with teaching staff.

To fulfil their role, the librarians are supported by the Academic Quality department that is required to sign off reviews and validations of programmes. They are also supported by SCONUL, The Society of College, National and University Libraries, which represents all university libraries in the UK and Ireland, national libraries and many of UK colleges of higher education. SCONUL promotes awareness of the role of academic libraries in supporting research excellence and student achievement and employability, and represents their views and interests to government, regulators and other stakeholders. It helps academic libraries collaborate to deliver services efficiently, including through shared services, and to share knowledge and best practice SCONUL members are the academic libraries themselves. SCONUL also has several groups supporting the strategy and ensuring that the academic library community is informed about, and engaged with, the major issues and challenges facing the library sector.

Librarians specialize in acquiring and negotiating directly with suppliers when prices rise too much. For managerial purposes, librarians prefer to administrate a package of small individual subscriptions rather than administrate these subscriptions individually. They only administer individual subscription/resources when these are heavily used. When appropriate, they delegate the negotiation and acquisition of the resources to buying organisations. For example, JISC seeks deals that all universities can go for, but they are often tiered, based on the number of students. JISC 
negotiate a national deal for many resources that universities use. Their negotiated deals are often preferred even if the price is slightly higher as they come with certain guarantees and quality. JISC suggests and acquires content for university librarians under their licensing terms when it offers better deals that are more suited to higher education. Occasionally, JISC purchase archives i.e. journals for the HEIs that universities can access for a low fee or free. University librarians would negotiate themselves with AMSR providers unless JISC gets a better deal.

\subsubsection{Managing sources of content}

The data analysis shows that university libraries are tied to big deals with publishers for some subscriptions. They can delegate the management of those sources individually to subscription management companies.

In addition, universities librarians are members of various university purchasing consortia, but also use offers from aggregators such as EBSCO and JISC. They have to manage their relationships with the different organisations. To support this, the Business Librarians Association (BLA) is involved in collating feedback on deals for JISC (but also sometimes negotiates deals with suppliers of content) and produce a benchmarking spread sheet which allows universities to see from members which resources are subscribed to. The BLA also receives complaints made by universities librarians about issues related to their relationships with suppliers of marketing and market research content.

\subsection{Budgeting marketing and market research content}

According to the interview data, the budget cycle is generally yearly, with decision making in the run up to the budgetary year, which in the UK usually runs with the overall university budgeting cycle from 1st August to the 31st July. Library budgets are allocated by department or school. When setting the budget, librarians will be looking to maximise the use of the resource by academics and students.

Interviewee 1 stated "An amount is given to our Department each year from the University and we allocate it to all the various funds needed and a portion of this to Departments also to spend on resources". 
Interviewee 5 stated "The budget is set by the head librarian. Later it is discussed with the librarians, in terms of what they need to spend if any new subscriptions are required and whether any other materials are required. Libraries have set budgets aside for subscriptions, all subscriptions will be good if they link to speific courses because they can be used by everyone in the university, so money spent on one archive subscription helps the whole university".

To buy resources for specific groups, the budget may come from other sources of funding in faculties.

Interviewee 8 stated that, to buy a resource, the budget is drawn "from the Library stock fund if the material is relevant to all. For specific groups it come from Faculty money".

Interview 10 stated "Budget is allocated at faculty level. There is also a university wide cycle as well. Fo the book budget, we have to spend by April to allow new stocks to come in on time and we have a new budget starting in August. Once I have an overall idea of the cost, it then goes to the procurement team. To me, the most accessible budget is the book budget".

\subsection{Pricing the content}

The data obtained from university librarians showed that whatever overall pricing strategy and tactics are is used (penetration, skimming, pricing by expected/perceived value of content bundles or individual content elements, scaling for size or number of users, straight pay as you go for individual items or bundles, freemium in which some content is paid and some is free etc.), pricing needs to be simple, ideally following JISC or similar policies, as practiced by most data providers. Overtly high pricing might create problems with content donors, so, it may be better to charge what is effectively an administration fee. Pricing to universities by existing research suppliers is typically $£ 500$ to $£ 2000$ for individual reports, with subscriptions being a minimum of $£ 2000$ up to $£ 20,000$. Usually, subscriptions have on -off payment options. Electronic forms of access bear VAT, and printed versions do not.

Promotional offers, which include the freemium model, the Free or discounted trial periods, academic discounts, often as much as $75 \%$, and deferred payment, can be very attractive, particularly 
for new sources, although universities strictly should not spend money in one year on resources that benefit the following year's students. Offered deals, including those from JISC, depend on the institution's size and how many students will access it. Every supplier has a different pricing model.

Interviewee 4 stated "I mean basically what we do is we research what we need, we look, at the pricing model for that particular resource and then we put that in the business case so really it's the finance department that decides whether we can get the extra money or not".

\section{Implications, limitations and future research areas}

The interviews with librarians provided insight about how AMSR could be distributed to universities libraries and how it can be accessed. The above findings contribute to understanding customer needs and shaping a new service product proposition. The findings are relevant to the archive material and the ways in which they can be marketed to users i.e. packaged, presented and customized to or by users and potentially linked to other content and applied to meet the academics, students and university librarians' requirements.

The interviews data highlight an interest in new service products e.g.. AMSR and show that university librarians are quite a product-oriented in their willingness to make AMSR available for users. AMSR is still at the earliest stages of its development. The potential AMSR service proposition could be extended to include more content such as (1) survey data for users i.e. researchers and students, for further analysis (subject to conformity to data protections laws), (2) interview data i.e. video and audio about oral history and practice, ebooks and guides, (3) online courses to help users from different disciplines understand how to use the AMSR material, and, (4) copies of new material that have used AMSR material e.g. research papers and dissertations, commissioned surveys and megatrend analysis. The extended AMSR proposition could also include sponsored content and advertising. To achieve this, the AMSR would need the support of its partners such as providers of content as well as the support of potential partners such as Analysts, think tanks and consultancies, Government bodies e.g. Office of National Statistics, Health and Social Care Information Centre, the National Institute of Health Research, universities and particularly the top-rated marketing 
departments with strong teaching and research in the discipline areas represented by the archive e.g. UCL Institute of Education Library - Kings Fund (for Health and Social Care), London School of Economics, Oxford's University's Bodleian library. The partnership with universities is important because students using the AMSR data could eventually become contributors to the AMSR content through submitting their dissertations in marketing and market research.

JISC could be an important partner as it is involved with archives - it covers 70 archives related to market research and 2180 archives with some kind of marketing content. However, two issues need to be taken into account if partnering with JISC is considered by AMSR. Some of JISC' archives overlap with AMSR's collections and are made available on open data basis, hence, free to users.

The interview data emphasise the role of aggregators in the research-based information acquisition. It could be of interest for the AMSR to consider selling the archive content to aggregators such as EBSCO or making it free to one or other archive hosting providers. The Business Archives Council could support and inform such decisions. Other potential partners could be Academy of Marketing Special Interest Groups, the Chartered Institute of Librarians Business special interest groups in areas such as academic and research, commercial legal and scientific, business, government and health, and also A Level Business and Economic case studies via the various UK school examination boards e.g. AQA, Edexcel.

Direct or indirect distribution of AMSR: the interview data collected from university librarians emphasise indirect distribution as an appealing option because of the key role of aggregators in ensuring the widespread use of research-based information in universities while getting payment for it. This does not rule out direct distribution to other markets, and certainly does not rule out direct contact for customers accessing AMSR material via aggregators. When content is paid for by libraries, it should appear in searches conducted using library search engines, even if it does not appear in more general searches. The AMSR could be distributed directly to universities. However, this option will require big improvements to the AMSR website in terms of usability, design, transaction management and analysis and in terms of indexing individual content so that it is found by search engines. This requires significant work, as indicated below. 
Another distribution option could be for AMSR to make some of its content available free and to fund itself by the sale of other content, and this strategy can be undertaken direct or via distributors. For this, AMSR must to consider the price that would be paid by potential aggregators, publishers and archive specialists (including JISC) to acquire its content i.e. individual items, and actual and potential compilations.

Communicating and selling direct to users: Direct digital communication is essential to promote the AMSR, whether the content is to be sold directly to users or to indirectly. This will involve developing the indexing to suit search engines (currently, searching for available AMSR documents failed to bring up the relevant document), short versions of content, regularly posted newsletters to keep subscribers up to date, and related blogs to highlight new and existing documents. Depending on financial and marketing objectives and performance, AMSR may need to use Pay Per Click advertising. If money is spent on acquiring the details of interested customers, then digital retargeting may be needed to try to convert prospects to sales. A common technique for providing better service on websites is to get users to classify their interests, so that relevant content can be served to them, rather than inferring it from their click pattern.

The AMSR could also develop the management of the CRM dialogue with users, setting up and promotion of content using social media pages as well as offering consultancy and other services relating to use of the archive. The usage of the AMSR website can be assessed using heatmaps representation of data where the individual usage of the website is plotted on a matrix. The performance of the AMSR website could be assessed using www.webpagetest.org. If the AMSR chose to sell subscriptions directly to universities, it is important to make the content accessible for students who are handicapped visually in some other way. Most universities require at least some form of conversion of text to speech to facilitate and adopt accessibility ways similar to what SCONUL and JISC are offering to Universities.

Pricing: The interview data emphasises the requirement of simplicity in the pricing of any content if AMSR distributes direct to libraries, whatever pricing strategy and tactics are used e.g. penetration, skimming, pricing by expected/perceived value of content bundles or individual content 
elements, scaling for size or number of users, straight pay as you go for individual items or bundles, freemium in which some content is paid and some is free. The AMSR could follow JISC or similar policies, as practiced by most data providers. However, overtly high pricing might create problems with content donors, so it is recommended that AMSR charge what is effectively an administration fee. AMSR could also sell memberships to individuals and institutions and allow members free access to all or part of the content. However, AMSR memberships might require a high level of service on the AMSR website and subscription details would need to be managed efficiently and to comply with data protection laws.

There is a need to further explore end-customer/user needs. The latter can only be established, in our view, by interviews with academic in relevant areas, initially with marketing/market research academics and then with academics in the other areas where the archive material might be interesting e.g. health, political science, history. In particular, it will be interesting to examine how university students and staff access and should access commercial research on marketing from the market research industry (in particular from the AMSR)) and use it in their learning, so that their knowledge will be more up to date and their employability will be increased..

\section{References}

Adams, R. J., P. Smart, and A. S. Huff. 2017. Shades of grey: guidelines for working with the grey literature in systematic reviews for management and organizational studies. International Journal of Management Reviews 19(4):.432-454.

Anderson, K. 2018. Focusing on Value - 102 Things Journal Publishers Do (2018 Update). Available on https://scholarlykitchen.sspnet.org/2018/02/06/focusing-value-102-things-journalpublishers-2018-update/. Accessed on July 23, 2019

Baker, S., and S. Holt. 2004. Making marketers accountable: a failure of marketing education?. Marketing Intelligence \& Planning 22(5): 557-567.

Brennan, R. (Ed.) 2004. Special Issue: The academic practitioner divide in marketing - myth or reality. Marketing Intelligence and Planning 22(5). 
Brennan, R., N. Tzempelikos, and J. Wilson. 2014. Improving relevance in B2B research: Analysis and recommendations. Journal of Business \& Industrial Marketing 29(7/8): 601-609.

Bryman, A. and E. Bell. 2015. Business Research Methods. 4th edn. Oxford: Oxford University Press.

Cordingley, P. 2008. Research and evidence-informed practice: focusing on practice and practitioners. Cambridge Journal of Education 38(1): 37-52.

Danneels, E., and G. L. Lilien. 1998. Doctoral programs in business-to-business marketing: Status and prospects. Journal of Business-to-Business Marketing 5(1-2): 7-34.

Deadrick, D. L. and P. A. Gibson. 2007. An examination of the research-practice gap in HR: Comparing topics of interest to HR academics and HR professionals. Human Resource Management Review 17(2): 131-139.

Eisenhardt, K. M. 1989. Building theories from case study research. Academy of Management Review 14(4): 532-550.

Ernst, J., D. M. Cooperstein, and M. Dernoga. 2011.Thought Leadership: The Next Wave of Differentiation in B2B Marketing. Forrester Research

Glassdoor. 2018. 15 more companies that no longer require a degree - Apply now. Last retrieved from https://www.glassdoor.com/blog/no-degree-required on April 1, 2019.

Gupta, D., and R. Savard (Eds.). 2011. Marketing libraries in a web 2.0 world. Berlin: De Gruyter Saur.

Huff, A. S. 2000. 1999 presidential address: changes in organizational knowledge production. Academy of management Review 25(2): 288-293.

Huggings, K. A. 2019. JME Highlights Current Lack of Digital Marketing Education, April 1, 2019. Last retrieved from https://socialmediamagnet.net/blog/articles/jme-highlights-current-lack-ofdigital-marketing-education/ on November 26, 2019

Hughes, T., D. Bence, L. Grisoni, N. O'Regan, and D. Wornham. 2012. Marketing as an applied science: lessons from other business disciplines. European Journal of Marketing 46(1/2): 92-111. 
Hughes, T., M. Stone, E. Aravopoulou, L. Tiu Wright, and L. Machtynger. 2018. Academic research into marketing: Many publications, but little impact?. Cogent Business \& Management 5(1): 118.

Hutt, M. D., and T. W. Speh. 2007. Undergraduate Education: The Implications of Cross-Functional, Relationships in Business Marketing-The Skills of High-Performing Managers. Journal of Business-to-Business Marketing 14(1): 75-94.

Jaworski, B. J. (2011). On managerial relevance. Journal of Marketing, 75(4): 211-224.

Johnson R., A. Watkinson., and M. Mabe. 2018. The STM Report. An Overview of Scientific and Scholarly Publishing. 1968-2018. Association of Scientific, Technical and medical Publishers, The Hague.

Joseph-Richard, P., and T. Jessop. 2018. A phenomenographic study of research informed teaching through the eyes of Masters' students. Studies in Higher Education, published online: 20 December 2018: 1-15.

Langan, R., S. Cowley, and C. Nguyen. 2019. The state of digital marketing in academia: An examination of marketing curriculum's response to digital disruption. Journal of Marketing Education 41(1): 32-46.

Lee, N., and G. Greenley. 2010. The theory-practice divide: thoughts from the editors and senior advisory board of EJM. European Journal of Marketing 44(1/2): 5-20.

Lilien, G. L. 2011. Bridging the academic-practitioner divide in marketing decision models. Journal of Marketing 75(4): 196-210.

McGann, J. G. 2019. 2018 Global Go To Think Tank Index Report. TTCSP Global Go To Think Tank Index Reports. https://repository.upenn.edu/think tanks/16

McDonald, M. 2009. The future of marketing: brightest star in the firmament, or a fading meteor?

Some hypotheses and a research agenda. Journal of Marketing Management 25(5-6): 431-450.

McDonald, M. 2003. Marketing died in the last decade. Interactive Marketing 5(2): 144-159. 
Miles M. B., and A. M. Huberman. 1994. Qualitative Data Analysis. Sage Publications, Thousand Oaks, CA.

Morais, R., L. Stoy, and L. Borrell-Damian. 2019. Big Deals Survey Report: An updated mapping of major scholarly publishing contracts in Europe. European University Assciation. Brussels and Geneva.

Nunan, D. 2017. Reflections on the future of the market research industry: is market research having its 'Kodak moment'?. International Journal of Market Research 59(5): 553-555.

Nunan, D. 2016. The declining use of the term market research: An empirical analysis. International Journal of Market Research 58(4): 503-522.

Nunan, D. and Di Domenico, M. 2019. Rethinking the market research curriculum. International Journal of Market Research 61(1): 22-32.

O’Brien, C. 2016. Missing the mark: The digital marketing skills gap in the USA, UK, \& Ireland. Last retrieved from https://digital marketinginstitute.com/en-us/the-insider/missing-the-mark-thedigital-marketing-skills-gap-in-the-usa-uk-ireland on April 1, 2019.

Ottesen, G. G., and K. Grønhaug. 2004. Barriers to practical use of academic marketing knowledge. Marketing Intelligence \& Planning 22(5): 520-530.

Pera, R., N. Occhiocupo, and J. Clarke. 2016. Motives and resources for value co-creation in a multistakeholder ecosystem: A managerial perspective. Journal of Business Research 69(10): 40334041.

Reibstein, D. J., G. Day, and J. Wind. 2009. Guest editorial: is marketing academia losing its way?. Journal of Marketing 73(4): 1-3.

Science Europe. 2018. Workshop Report - Challenging the Current Business Models in Academic Publishing: Accelerators and Obstacles to the Open Access Transition. Science Europe. Brussels. 
Scimago. 2019. Scimago Journal and Country Rank (marketing selected), available on https://www.scimagojr.com/journalrank.php?category=1406, Scimago, Madrid.

Stott, R. N., M. Stone, and J. Fae. 2016. Business models in the business-to-business and business-toconsumer worlds-what can each world learn from the other?. Journal of Business \& Industrial Marketing 31(8): 943-954.

Sheoran, M., D. Kumar, V. Kumar, and D. Verma. 2018. Understanding the trends of marketing research and its future directions: a citation analysis. The Bottom Line 31(3/4): 191-207.

Stern, B. L., and L. D. Tseng. 2002. Do academics and practitioners agree on what and how to teach the undergraduate marketing research course?. Journal of Marketing Education 24(3): 225-232.

Stone, M. 2013. Co-operation between academics and practitioners-hope for the future?. Journal of Direct, Data and Digital Marketing Practice 15(2): 105-107.

Stone, M., N. Woodcock, Y. Ekinci, E. Aravopoulou, and B. D. Parnell. 2019. SCHEMA: Information on marketing and customer engagement performance-reality versus dreams. The Bottom Line 32(1): 98-116.

Tracy, S. J. 2010. Qualitative quality: Eight “big-tent” criteria for excellent qualitative research. Qualitative inquiry 16(10): 837-851.

Tranfield, D., D. Denyer, and P. Smart, P. 2003. Towards a methodology for developing evidence-informed management knowledge by means of systematic review. British Journal of Management 14(3): 207-222.

Yi, Z. 2018. Effective techniques for marketing electronic resources. The Journal of Academic Librarianship 44(4): 446-454.

Yin, R. K. 2013. Validity and generalization in future case study evaluations. Evaluation 19(3): 321332.

Zott, C., R. Amit, and L. Massa. 2010. The Business Model: Theoretical Roots, Recent Developments, and Future Research, Navarra, Spain: IESE Business School Working Paper No. 862. 